\title{
Attempt to Extend Knowledge of Decision Support Systems for Small and Medium-Sized Enterprises
}

\author{
Jerzy Korczak, Helena Dudycz, Bartłomiej Nita, Piotr Oleksyk, Adrian Kaźmierczak \\ Wrocław University of Economics Komandorska Str. 118/120, \\ PL 53-345 Wroclaw, Poland \\ Email: \{jerzy.korczak, helena.dudycz, bartlomiej.nita, piotr.oleksyk, adrian.kazmierczak\}@ue.wroc.pl
}

\begin{abstract}
The article presents a proposal to extend the functionality and knowledge of Business Intelligence systems to answer the requirements of managers of small and mediumsized enterprises (SMEs). It concerns two major aspects of the system, i.e. the interface that takes into account the level of knowledge of the manager, and supports the interpretation of economic and financial information using the built-in domain ontologies. The project is related to the design of smart decision support systems based on financial ontology and on the model of manager knowledge created by eye tracking analysis. An experiment was carried out on real financial data extracted from the database of Business Intelligent BINOCLE, developed by Bilander Co. To create a model of manager knowledge, a number of financial analysts, experts and economists were invited to analyze the pre-defined financial reports. Their tasks were observed and analyzed by the eye-tracking system StudioTM, Tobii. The logs of the system as well as the financial ontology have been used to develop the intelligent interface of a Decision Support System.
\end{abstract}

\section{INTRODUCTION}

$\mathrm{D}^{\mathrm{s}}$ ecision-making in small and medium-sized enterprises is an extremely difficult process. The most important problems of the functioning of such enterprises are operational continuity, ensuring the ongoing customer service and support as well as technological aspects. Managing a business requires access to the appropriate information system that must always go hand in hand with the methods of financial analysis, allowing managers to monitor the changes in the environment, identify the different types of risk, choose appropriate forms of insurance against these risks, and follow appropriate scenarios of development. Each of the scenarios predicts future financial situations using the methods and tools of financial analysis. Managers of small and mediumsized enterprises (SMEs), on the one hand, are usually confronted with the barriers and limits on information, and on the other hand are able more easily to control costs and expenses using an individual, simplified information processing system, regardless of the requirements of accounting standards. It may be difficult for them to access

1 Eye tracking is a collection of techniques for the measurement, acquisition and analysis of data about the position and movements of the prospective information allowing the evaluation of the anticipated environment changes.

Managers of SMEs need solutions that support their decisions based on transactional data which, after being processed by the tools of financial analysis, allow them to prepare the draft of decision. Today's information technology assures managers access to the multi-dimensional data stored in various data-bases and enables them to perform multicriteria analysis. The problem appears, among others, to lie in the excessive numbers of reports which are generated by transactional and executive information systems. In the process of management, the information overload significantly reduces the ability to make the right decision.

In SMEs, financial forecasts needed to make good business decisions oriented towards improving financial efficiency and dynamic development are very often prepared in a cursory manner or simply ignored. This is mainly due to lack of time, and not to sufficient and limited managerial knowledge.

The aim of the article is to point out the possibilities of building the model of financial knowledge for managers in Business Intelligence system using eye tracking tools ${ }^{1}$, and applying the model to interpret reported economic data. Data from eye-tracking illustrates not only the perception of the economic reports by a manager, but also enables the manager to identify schemes analysis and determine the level of his or her knowledge. It facilitates also the establishment of a manager knowledge profile and, consequently, it creates a possibility of adapting the interface to an individual's skills. In the project, the whole process of analysing financial data will be supported by built-in ontologies of economic and financial knowledge which is essential for SME managers. This will be possible thanks to research focusing on the development of an intelligent interface supporting interpretation of economic information, which also is associated with modeling of managerial knowledge. The described approach is a continuation of the construction of the intelligent cockpit for managers (InKoM project), whose main objective was to facilitate financial analysis and the

eyeballs. It provides a quantitative measurement without referring to subjective, verbal relationships of the respondent [http://eyetracking.pl]. 
evaluation of the economic status of the company on a competitive market [1].

The structure of the article is as follows. The next section focuses on the issues related to management-based analysis, particularly in relation to SMEs. The next section briefly refers to the Business Intelligence (BI) system in the context of the Key Performance Indicators (KPI) used to build an ontology of economic and financial knowledge. Section 4 is devoted to the modeling of managerial knowledge, together with a synthetic description of the eye-tracking results. The article concludes with a summary of work to date.

\section{SUPPORTING OF MANAGERIAL ANALYSIS}

Management of the SME is a very complex and difficult task. In such organizations, resources for wider financial and accounting services are usually limited. Often, these tasks are assigned to accountants who are excessively burdened with operational activities and supervision of the correct tax settlements. Managers of SMEs often have to focus on the technological problems related to the core business, which limits the possibility of financial projections associated with the preparation of the right decisions to ensure financial security and dynamic development based on improving financial efficiency.

Financial analysis allows the interpretation of the information necessary for the ongoing management of an enterprise $^{2}$. Managers of SMEs are expected to find support in the following areas:

- assessment of the project's effectiveness - the answer to the question whether the achieved profits are adequate to the funds involved, and how to compare the results with other companies with similar operations;

- assessment of cash flows - whether it is possible to repeat a generated surplus in the following periods or whether it will no longer occur in the future.

The main activities of the SMEs are focused on business operations. Information processing and related decisions concern the core activities of the company, and are associated with its specificity and membership in a particular industry. An important element of operational management in SMEs is to control liquidity, while it should be emphasized that classical liquidity ratios used in large companies cannot be always directly applied to SMEs. In this view it is worth designing solutions that make use of analytical accounting records to project liquidity on a monthly basis. There is no doubt that this kind of analysis of liquidity, taking into account the size of the entity, the specificity of the industry, and the type of offered products or services is not possible

\footnotetext{
2 It should be emphasized that the selection of appropriate methods of analysis of the financial requirements of SME managers is necessary to determine the company's ability to continue its operations, and to define financial needs, budgets and capital resources of financing assets, signs of danger and risk of changes in the competitive position and trends in various business areas.
}

without expert knowledge. On the basis of empirical studies we found that information requirements for short term management concern [2] information about liquidity, information on revenues generated by the company, and information on costs incurred. But for the long-term management area, information is needed: about the company's indebtedness, about the profitability of planned investments, and about the financial situation of the branch.

The process of decisions support made needs - firstly - the decomposition and the proper selection of management instruments. Managing medium-sized enterprises requires information about the possibility of gridlock preventing stable business in the near future. Secondly, there is a need to acquire information to generate the appropriate level of profit and a minimum level of margins in order to make the right choices. They are focused on obtaining information on opportunities to increase revenue or to carry out activities aimed at cost minimization.

Regarding long-term decisions, managers of small companies are not able to relate to the use of advanced solutions for e.g. capital budgeting. They need analytical models that enable them to identify signals indicative of the need for investment decisions and the level of resources involved. With regard to medium-sized enterprises, this type of analysis should be augmented by simulations on the effectiveness of individual organizational units (responsibility centers) and the profitability of equity involved.

Acquisition of information to support such decisions is possible mainly through the use of patterns developed by experts in financial management. Unfortunately, it is impossible in this case to use the universal solutions - in this case it is necessary to dispose over an intelligent system that using expert knowledge provides ready-made decisions, taking into account the specific nature of the company ${ }^{3}$.

Also important are analysis of the index of debt level and the use of static and dynamic methods of estimating the profitability of investment. For organizations with greater economic importance, the study should be completed by:

- the use of the Balanced Score Card and the early warning system,

- analysis of indicators of debt service, study of the cost of capital: domestic and foreign capital, the weighted average cost of capital,

- pro-forma financial statements - as information about the financial effects of planned long-term actions,

- evaluation of the company's profitability: return on sale ratios, return on assets and equity - to various cuts in the financial results,

\footnotetext{
The management of long-term financial analysis conducted by managers of small businesses should include: a preliminary analysis of financial statements, ratio analysis, information on liquidity ratios, evaluation of static measures of liquidity, turnover ratios of inventories, receivables and payables analysis, analysis of the operating cycle in terms of the efficiency of indicators of capital engagement, productivity of assets and equity, and information on current and future income and expenses.
} 
- methods of budgeting process.

Generally, the support of decision-making is based on the generation of ready-made paths, together with projections of the effects of planned decisions. For example, in a system of the Binocle Bilander company which is classified as a category of Business Intelligence systems, there are many useful and powerful functionalities that make possible multivariate analysis of financial data. However, due to the limited resources of SMEs, it is necessary to develop readymade reporting and decision paths for managers and owners of SMEs. These reports and patterns of decision-making should take into account inter alia the support for operational and financial planning, and risk analysis (in particular, the risk of bankruptcy). In addition, they may include support in investment decisions and measuring the effectiveness of the company as a whole and its individual organizational units.

In addition, to improve the decision-making processes in SMEs, three important issues should be taken into account:

- number of KPIs (key measures of achievement),

- methods of forecasting and simulation to facilitate taking corrective actions,

- standard indicators for SMEs needed for benchmarking.

Also crucial is a selection of available reports (option in the Binocle system) to present the most important information for the manager. If needed, these reports may be further detailed.

\section{KPI IN BUSINESS INTELLIGENCE SYSTEMS}

Both in business practice and in literature one can find different definitions of Business Intelligence (BI). The main goal of each form of BI is to gain access in a timely manner to relevant data to allow making the best decision at a given time [3; 4]. An important element of BI systems is also the visualization of the calculated KPIs. These indicators are the basis of decision-making both at strategic as well as tactical and operational level. The usefulness of indicators depends on the manager's understanding of the concepts, measures and structural links involved. Leading financial analysis of the indicators the manager examines their semantic relationships. The essence of the evaluation is the appropriate computing and use of indicators derived from different financial statements (including balance sheet, profit and loss statement,...). The usability of economic analysis depends on, among other things, the manager's exact understanding of the existing structural semantic links, and relations between indicators and economic terms. According to the degree of data aggregation, the measures might be global or partial, where the indicators can be summed up, differentiated, multiplied or divided.

Ratio analysis used to assess the activities of the company has both advantages and disadvantages. Among the first are: the ease of measurement, the availability of source data, the ability to identify critical areas of economic activities, the universality of the indicators, allowing, among other things, the conduct of comparative analyses with other companies.
While the disadvantages are: no indication of the reasons for unfavorable events, the risk of misinterpretation of measures, the lack of universal standard ratios. Finding the causes of adverse events, and taking note of the positive factors, can facilitate the evaluation of the data by analyzing the semantic relationships between economic indicators.

Most BI systems (referred to as traditional BI systems or BI 1.0) are primarily intended for managers who are familiar with data models and are able to build all kinds of scenarios analysis [5]. The literature points to the creation of the next generation BI systems, known as Business Intelligence 2.0 $[6 ; 7]$. These systems are characterized by properties such as event management and analysis in real-time, direct access to information at different levels of enterprise management, predictive analytics, enhanced interactive visualization, intuitive interface, support for semantic information retrieval, and widespread and mobile access data (described in [6]). A characteristic feature of this new generation of BI systems is the reliance on the ontology and semantic retrieval of information. In architecture, there are new elements, such as ontology, ontology services and application domain ontology. The use of ontologies and visual information retrieval within analytical tools can be helpful to solve the following problems [8, p. 215]:

- definition of business rules in order to get proactive information and advice in the decision-making process,

- specification of semantic layer describing the relationships between different economic concepts,

- presentation of business information,

- the rapid modification of existing databases and data warehouses.

Development of BI systems is progressing towards the use of visual information retrieval based on a semantic Web. One of the main artifacts in the emergence of the semantic Web is an ontology. In the framework of the project we have elaborated the ontology, covering the scope and the data discussed in the paper.

\section{ONTOLOGICAL FOUNDATION}

One way to represent knowledge in information systems is an ontology. In the literature, you can find many definitions of ontology. However, most often the term refers to the definition given by T. Gruber, who describes it as "an explicit specification of a conceptualization“" [9, p. 907]. So ontology is a model that defines formally the concepts of a specific area and the semantic relations between them. In literature research of an ontology using in BI systems are described [10; $11 ; 12 ; 13 ; 14 ; 15]$.

Many research projects show that creating an ontology of economic and financial indicators is advantageous in decision making [8]. This is important, because there is no single universal system of economic indicators that would be used in all organizations. Besides, a lot of companies use a number of assessment models of business based on the analysis of various indicators. An ontological approach to modeling 
domain knowledge was proposed in the project "Intelligent dashboard for managers (InKoM)" (described in $[1 ; 16])$. The main objective of the project was to create an intelligent cockpit for managers of small and medium-sized enterprises, which facilitates analysis and interpretation of the economic situations of the company, and supports analysis of economic and financial data Three new components of the cockpit are important: the financial ontology, the data mining algorithms, and the mechanism of deep retrieval on the Internet. This solution has enabled adequate, expandable and adaptable mapping of economic and financial knowledge, without having to modify the existing system of TETA BI. The new system significantly extended the usefulness of the existing Decision Support System [17].

In developing an intelligent interface, the ontological approach was completed by eye-tracking methods. Available in the BI system, a visual presentation of data permits one quickly to assess the economic situation and take appropriate action. To discover a way of analysing financial reports and statements managers, financial analysts, and students of economics participated in the experiments. The eye-tracking logs during the reading of these documents were used to discover the patterns of operations and to model the financial knowledge of each of the participants. The concepts and analytical operations performed by each manager were matched with the financial ontology available in the system.

\section{CASE STUDY - EVALUaTiOn OF A COMPANY'S PROFITABILITY}

Profitability analysis is necessary to assess the effectiveness of an economic entity. Sales revenues are essential to generate cash inflows that feed any company. These cash flows are used not only to purchase materials, services, and other goods, but also to make investments in fixed assets and working capital necessary to sustain ongoing operations. Profit is, however, a universal measure used in assessment of the financial situation. Unfortunately, the fact that an increase in revenues and earnings does not always generate cash inflows triggers off a serious risk of misinterpretation. Thus, the lack of cash inflows may generate serious financial problems. Profitability analysis without taking into account changes in cash position may yield wrong business decisions [18]. This is why the use of an ontology that describes in detail the issue of profitability allows one to avoid the risk of misinterpretation.

Managers of SMEs require a strong semantic reach and easy to use methods and techniques to support decision making. The aim of the experiment was to examine the usefulness of a financial ontology in the analysis of selected financial indicators and metrics in supporting operational decision making. Participants in the experiment had access to the system containing financial reports and ontology diagrams supporting the analysis of corporate profitability. For the purposes of our research, the balance sheet and profit and loss account of a real company were submitted. The financial statement included information that indicated the seemingly positive performance of the case company. In the periods analyzed, however, serious problems occurred due to bad debts. Those problems should have been perceived by the analyst as threatening the loss of the rationale behind the going concern's basic assumption, i.e. the ability to function without the threat of liquidation for the foreseeable future.

The experiment was initiated by the analysis of an internal managerial report containing widely used measures of financial situation, namely: liquidity profitability, debt, and turnover ratios. The most important factor directly observed by the participants of the experiment was a significant increase in profitability in the analyzed period.

In order to explain the profitability ratio correctly there was a need to take advantage of the ontology describing the issue of profitability, which is presented in Figure 1.

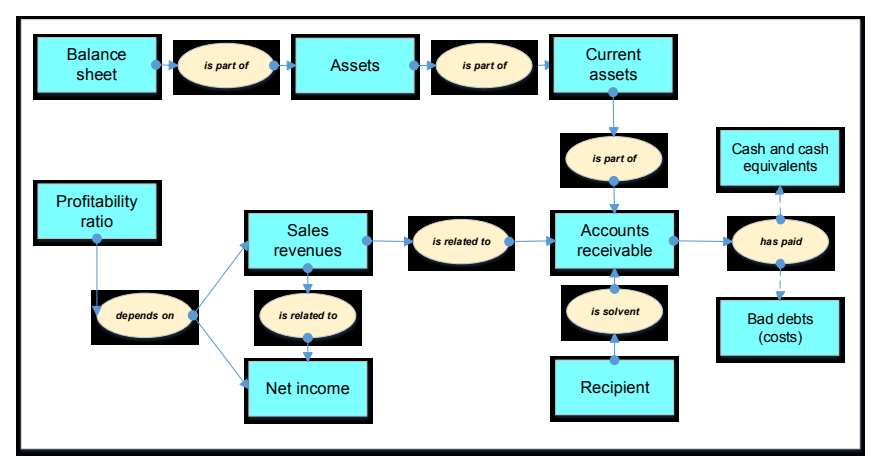

Fig. 1. Ontology: view of profitability

Profitability is the most important measure of effectiveness while running a business. According to the scheme presented in Figure 1, profitability is dependent on sales revenue and total net profit earned by the company. The aim of profitability analysis is to obtain information about the amount of the surplus earned from the sale which remains at the disposal of managers. Ontology describing corporate profitability allows the manager to properly analyze the growth of profitability ratio. It is necessary to examine the increase in revenues, net income as well as changes in cash amount and accounts receivable. According to the ontology, an increase in both profitability and accounts receivable is an unfavorable symptom. A positive sign suggested by the ontology was the increase in profitability along with the increase in cash.

Rate of return on sales is one of the key measures of operational efficiency, which informs us about the margin that has been realized on sales. Increasing ratio of return on sales is a positive symptom for the company because it may confirm that the proper decisions were made with regard to cost reduction or making good business deals allowing the company to increase sales revenues in excess of costs [19, pp. 135-164].

Profit margin, on the one hand, indicates the actual part of company revenues which remains at the disposal of managers and contributes to cover operating costs. On the other hand, profit earned may be used to increase equity or be paid out to the owners as dividends. The greatest disadvantage of return on sales ratio is that it is computed on the accrual basis [20]. 
The most fundamental concept of accounting is accrual principle that is a requirement of both International Financial Reporting Standards and Generally Accepted Accounting Principles. This concept requires keeping a record of business transactions (such as the rise in revenues or accounts receivable) in the period in which they actually occur, not in the period in which the cash flows related to them occur.

This means that sales transactions recorded as revenues in the accounting system increase net income, which, however, due to various external factors, may never be realized in the form of actual cash inflows (e.g. due to the bankruptcy of the recipient or the initiation of legal proceedings on claims, etc.).

According to the ontology presented in Figure 1, as the profitability increases it is necessary to check whether the increase in revenues is reflected in actual cash flows which are needed in running a business on a daily basis. Increase in profitability may be also triggered off by the increase in accounts receivable, which might be perceived as an unfavorable symptom.

Cash inflows from sales are the most important components of cash flows from operating activities as, in the opinion of many scholars, the most important element of cash flow statement, because in this part information about the most common business operations has been aggregated. This is a segment which usually generates excess cash that is used to finance investment processes, and to purchase fixed assets and intangible assets, as well as to repay financial obligations [2]. The shortage of cash flows from operating activities occurring in subsequent years should be perceived as an unfavorable symptom, because that usually indicates impending bankruptcy if the appropriate remedial steps are not taken.

The problem that causes significant misinterpretations in the proper assessment of the rate of return on sales is the issue of the so-called bad debts. The most common reason for the financial problems of many small and medium-sized companies is a problem with collection of accounts receivables. In such cases credit risk is understood as a potential loss due to the lack of collection of receivables. According to legal requirements in Poland, if there are any doubts with regard to the possibility of collecting receivables, these should be regarded as uncollectable bad debts. Thus, bad debts are those whose probability of recovery is low or close to zero. These accounts are a serious problem for the company, because they require to deal with impairment as well as legal enforcement proceedings that may be problematic.

In the experiment, it was noted that the increase in profitability is due to the accrual principal, and thus virtual, because as revenues significantly increased, accounts receivable increased even more, as presented in Figure 2. The decision maker using financial reports and ontology is guided through analytical steps, which are labeled on Figure 2 with numbers from 1 to 8 .

In the analyzed period, sales revenues increased from 732 thousand PLN to 813 thousand PLN. According to the ontology, it is not recommended to base analysis solely on revenue growth, because the comprehensive analysis must include the detailed examination of changes in receivables. In the analyzed period, accounts receivable in the balance sheet increased dramatically from 145 thousand PLN to 321 thousand PLN. Thus, the ontology allows to avoid a threat of misinterpretation with regard to an apparent increase in profitability.

Financial analysis of a company's standing should be comprehensive. The example of such analysis with regard to profitability is presented in Figure 2. Based on the ontology, it is not sufficient to analyze managerial reports containing financial indicators, but it is necessary also to focus on the selected items from the financial statement. In order to properly explain the increase in profitability, the analyst is required to deal with percentage change analysis with regard to:

- revenues from sales,

- net income,

- short-term receivables,

- cash and cash equivalents.

Comprehensive analysis of the most important factors affecting the level of profitability ratio should be completed by sending a warning signal from the decision support system. As presented in Figure 2, the warning signal indicates that there is a need to take a decision to amend the sales process management. In the analysed case, in order to improve average collection of receivables it is recommended to:

- apply debt collection and enforcement techniques (in a short-term transaction),

- look for customers in different market segments, who do not have problems with paying on time (in a long-term one).

Suggestions proposed by the decision support system should be considered against the market conditions and customs of the local industry. Excessive use of debt collection activities can generate a negative signal to potential new customers who will search for suppliers among competing companies patiently waiting for payment. Such actions to be taken by managers were suggested by means of the warning signal generated by the system as it was presented in Figure 2.

Changing the segment of the target market may be feasible in the long term, thus such a decision should be preceded by insightful analysis. Moreover, it is necessary to examine the potential impact of restructuring on the future performance of the company. In addition, it is necessary to analyse the company's ability to carry out the investment project oriented towards the company's adjustment to new customers.

Any decision should be revised using the same techniques that helped to identify the original problem. In our experiment, we studied the financial performance demonstrated by the company that was achieved in the subsequent period. In Figure 3, we present an analysis of the research findings and their interpretation. 

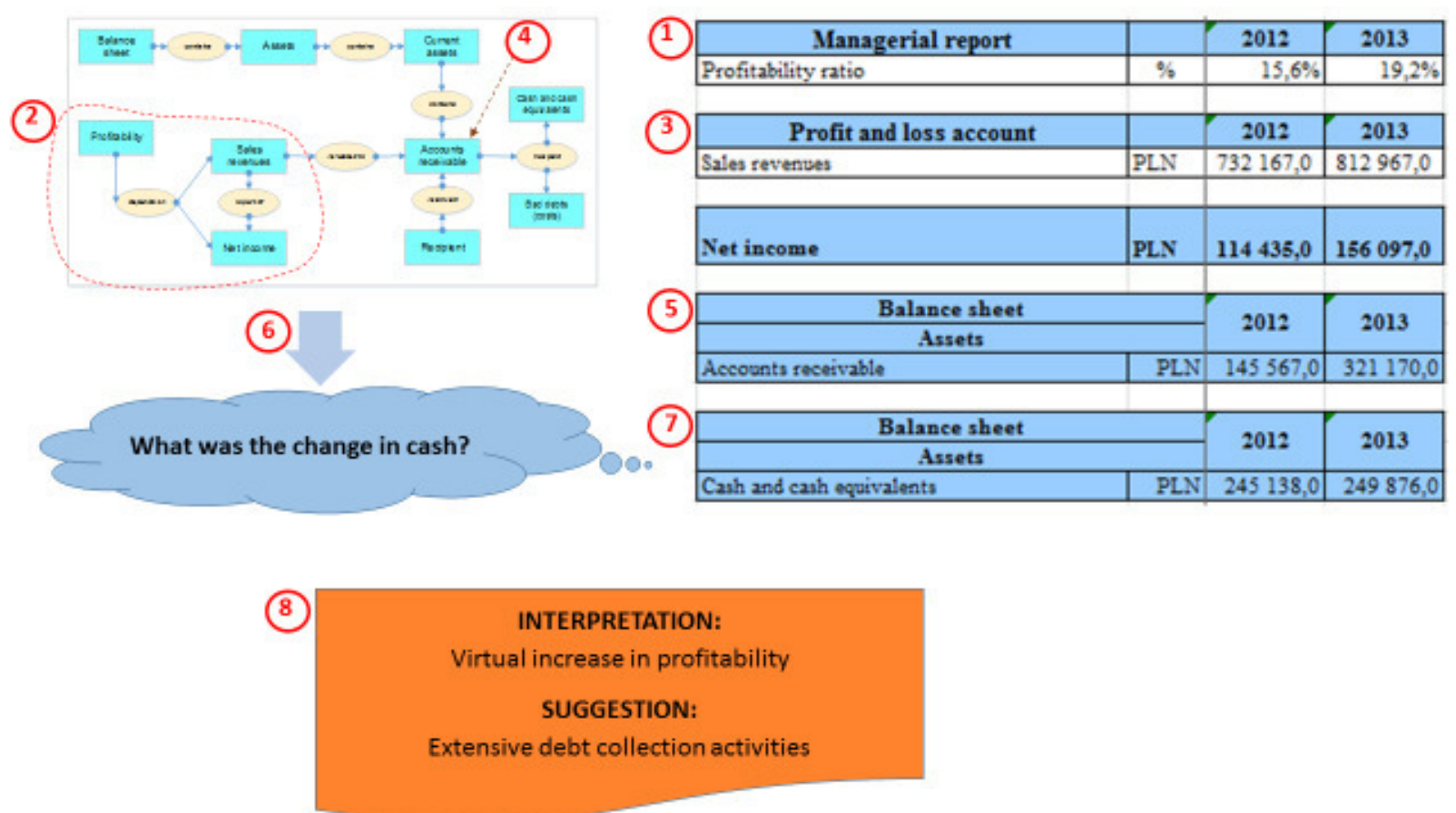

Fig. 2. Supporting the proper interpretation of profitability ratios (task 1)

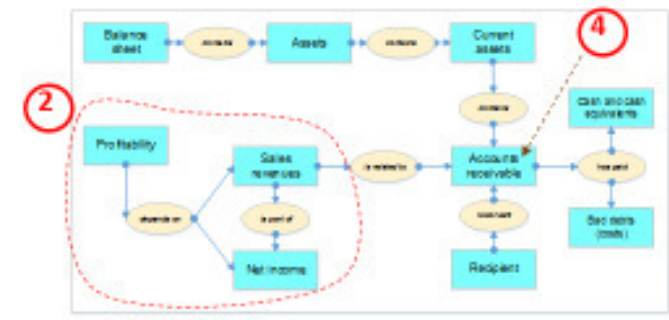

(6)

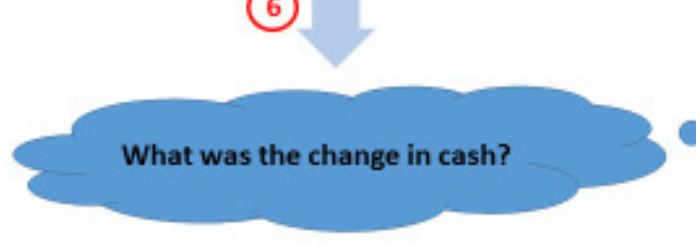

\begin{tabular}{|c|c|c|c|}
\hline Managerial report & & 2013 & 2014 \\
\hline Profitability ratio & $\%$ & $19,2 \%$ & $21,6 \%$ \\
\hline Profit and loss account & & 2013 & 2014 \\
\hline Sales revenves & PLN & 812967,0 & 978045,0 \\
\hline Net income & PL.N & 156097,0 & 211078,0 \\
\hline Balance sheet & & & \\
\hline Assets & & 2013 & 2014 \\
\hline Aceounts rectivable & PLN & 321170,0 & 339067,0 \\
\hline Balance sheet & & 9 & 40 \\
\hline Assets & & 2013 & 2014 \\
\hline Cash and eash equivalents & PLN & 249876,0 & 311479,0 \\
\hline
\end{tabular}

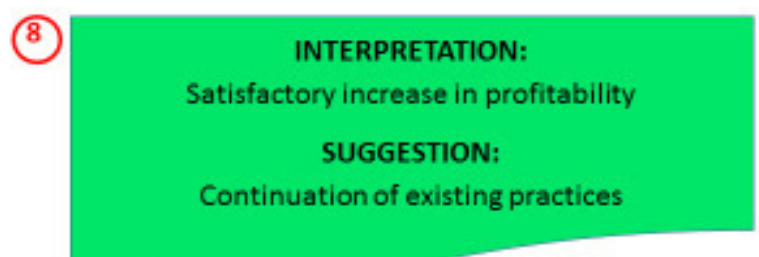

Fig. 3. Supporting the proper interpretation of profitability ratios (task 2)

Analysis of the solutions applied in the previous period allows them to be considered as accurate. Figure 3 presents the performance of the company, among which the most important signal is the increase in sales revenue and the 
increase in cash flow. Simultaneously, the level of accounts receivable has stabilized. Figure 3 presents the financial performance of the case company. Similarly to Figure 2, in Figure 3 we labeled analytical steps to be performed by the decision maker with numbers from 1 to 8 . Among other measures, the most important signs are the increase in revenues from 813 thousand PLN to 978 thousand PLN and an increase in cash amount from 250 thousand PLN to 311 thousand PLN while the short-term receivables amounts remained stable (not exceeding 10\%).

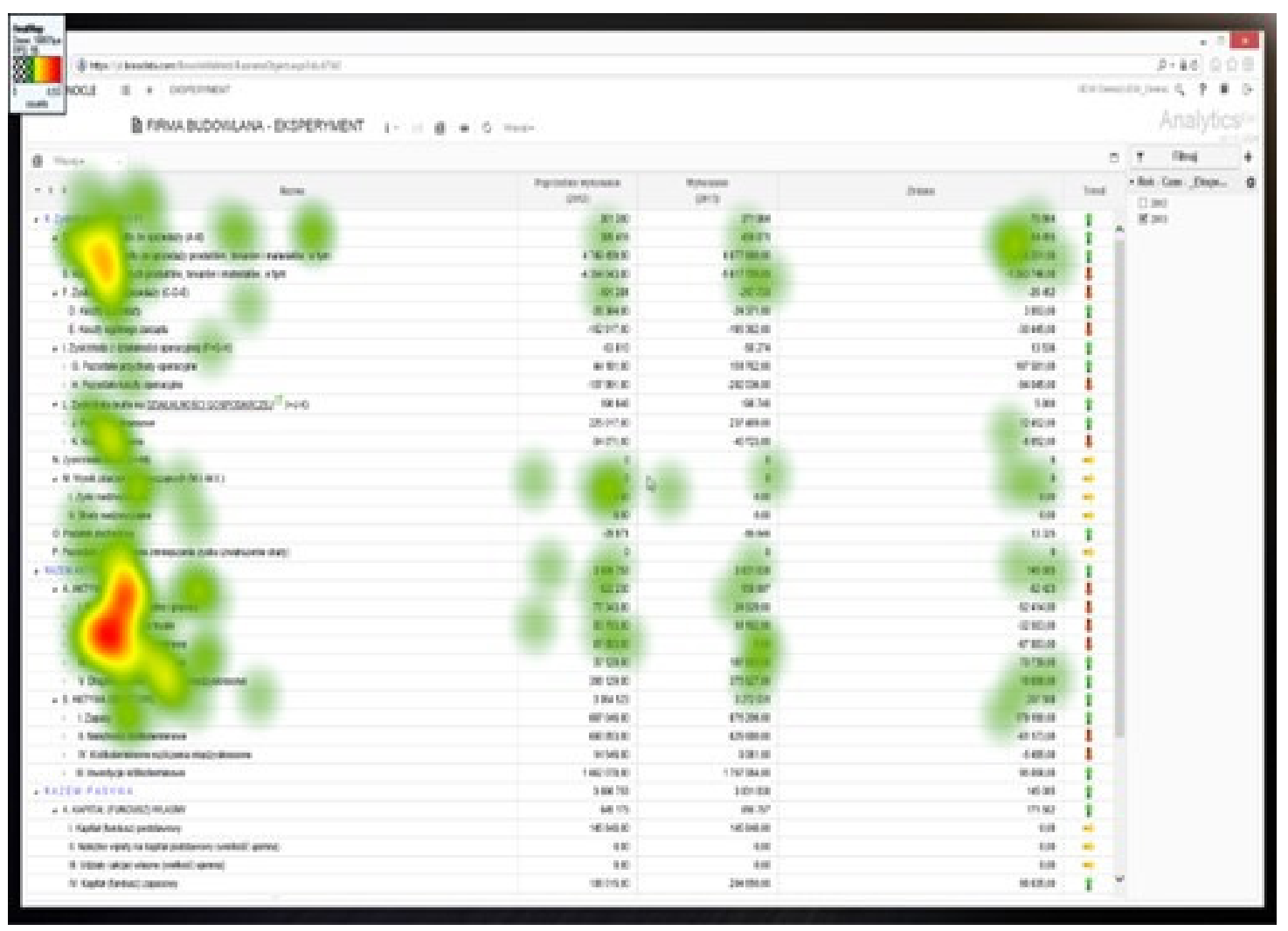

Fig. 4. Example heat map

This highlights the relevance of decisions taken by means of a decision support system based on a developed ontology. The proper interpretation of the information contained in the financial statements varies depending on the qualifications of novices and experienced managers. Novices only paid attention to the increase in revenues and profit growth, but neglected the change in accounts receivables. Most of the experienced managers focused their attention on the growth of accounts receivables. The behavioral patterns of experienced managers confirmed the usefulness and comprehensiveness of the ontology. Bad debts are a serious problem which should be analyzed first, before the revenue growth. Decision making without the use of ontology may lead to wrong conclusions, e.g. introducing sales promotion to increase sales growth. Using the ontology enabled the appropriate decisions to be made with respect to receivables management.

Comprehensive insight into both the selected managerial indicators and metrics as well as the changes in the value of chosen items from the financial statement is required for the proper interpretation of a company's performance. This would not be possible without the use of systematic knowledge in the form of ontology. Ontology is therefore an essential element of the decision support system that allows us to make the right business decisions oriented toward company development and avoiding the threat of bankruptcy.

\section{APPROACH TO MODELLING OF MANAGERIAL KNOWLEDGE}

In the construction of a new decision support system interface, an important role is played by the manager profile, in particular identifying his or her financial and economic knowledge. There are a number of methods for knowledge and reactions modelling of managers: crowdsourcing [21], testing physiological brain [22], explorations of the observation of the manager's eye movements, otherwise called eye tracking. In the project this last test method was applied. Eye tracking provides the opportunity to obtain various results, among which may be mentioned: the raw data, the scanning path, and a heat map. Figure 4 illustrates the sequence of analysis of the Balance Sheet by a manager. The diagram shows the parts of the document which have particularly attracted the attention of the manager: the area 
close to the color red. Green areas on the thermal map show other areas for attention.

The results of the experiments raised three questions: (1) how and why does the experienced manager proceed; (2) how to identify the short-comings and errors committed by inexperienced managers, and (3) how to recognize a manager's fatigue and stress. The answers to these and other questions provided patterns of schematic perception of economic information. Using process mining methods, the preliminary rules and sequences of activities were discovered for novices and managers with experience. Raw quantitative data, collected by tracking software, can be analysed and used in the process of searching for perception patterns. As a result of the transformation of the data, it is possible to obtain a model of the analytical operations of managers. Such data, along with analytical models and ontology of financial analysis, are the basis of an intelligent decision support system. Patterns, models of financial analysis, and ontology are considered as knowledge in an intelligent financial decision support system.

\section{CONCLUSIONS AND FUTURE RESEARCH}

This article presents a new attempt to create an intelligent interface for a Decision Support System. The idea was founded on the use of domain ontology and methods of patterns discovery of managerial knowledge from eyetracking logs. The studies show that managers of small and medium-sized enterprises often have little benefit from achievements in the field of broadly understood financial analysis and IT technology, to strengthen their competitive position on the market and maintain financial credibility. The problem is often caused by the lack of the knowledge required to correctly interpret the financial reports as well as economic indicators. Also, they have difficulty with the knowledgeable use of the information systems that contain too many functions and tools that exceed their knowledge and skills. Usually, numerous ways of reporting, and the complex visualization tools, deepen the difficulties in the perception of the financial situation of an enterprise and its environment.

The use of improved visualization and access to semantic searches are primary characteristics of the BI 2.0 system. One of the main artefacts in semantic networks is the ontology of business information. A created ontology is required in which data and relationships of objects from various fields of knowledge are defined.

The experiments showed the usefulness of ontology where each concept and relationship can be considered in a multifaceted way. In the case studies, we have demonstrated that decision making without the use of ontology may lead to wrong conclusions, e.g. introducing sales promotion to increase sales growth. Analysis of indicators alone without relation to other components of financial reporting can lead to the choice of improper interpretations. Ontology is therefore an essential element in the decision support system that allows a manager to make correct business decisions oriented toward company development and avoiding the threat of bankruptcy.
The use of eye-tracking allowed us to develop preliminary patterns of analysis of financial reports and interpret the most important indicators.

The sequences of actions, discovered on the basis of the eye-tracking of experts, allows for defining of best practices to analyze financial data. However, these patterns are not sufficient to generate the interface. They must be associated with the financial ontology that help to interpret the data and provide adequate recommendations.

Preliminary results of the experiments demonstrated large differences between the experienced managers and novices in the manner of data perception and a way of analysis of financial reports. To develop a user-oriented interface, further in-depth studies on identifying the level of manager knowledge are needed. The project will be continued, especially on modeling of manager knowledge using eyetracking. Models of patterns exploration in analytical sequences of actions will also be developed.

Acknowledgements. The authors thank the staff and the companies Bilander and Tobii for their support in developing the prototype. Thanks go also to the financial experts: Wojciech Hasik, Mariola Kotłowska and Wojciech Ostojski, and students of the Faculty of Management, Informatics and Finance of Wrocław University of Economics.

\section{REFERENCES}

[1] J. Korczak, H. Dudycz and M. Dyczkowski, "Intelligent dashboard for SME managers. Architecture and functions", in: Proc. of the Federated Conference on Computer Science and Information Systems, M. Ganzha, L. Maciaszek, M. Paprzycki, Eds., Polskie Towarzystwo Informatyczne, IEEE Computer Society Press, Warsaw, Los Alamitos, CA, 2012, pp. 1003-1007

[2] M. Samonas, Financial Forecasting, Analysis and Modelling, John Wiley and Sons, Chichester 2015

[3] H. Dudycz, Visualization methods in Business Intelligence systems An overview, Business Informatics (16). Data Mining and Business Intelligence, J. Korczak, Ed., Research Papers of Wrocław University of Economics, 2010, no. 104, pp. 9-24.

[4] D. Sell, L. Cabral, E. Motta, J. Domingue and R. Pacheco, Adding Semantics to Business Intelligence, 2008, http://dip.sema.nticweb.org/documents/WebSpaperOUV2.pdf.

[5] N. Raden, Business Intelligence 2.0: Simpler, More Accessible, Inevitable, 2007

http://www.informationweek.com/news/software/bi/197002610

[6] S. Nelson, Business Intelligence 2.0: Are we there yet? SAS Global Forum, 2010

http://support.sas.com/resources/papers/proceedings10/040-2010.pdf

[7] J. Trujillo, A. Mate, Business Intelligence 2.0: a general overview, in: Business Intelligence: First European Summer School, eBISS 2011, M.A. Aufaure, E. Zimanyi, Eds., Lecture Notes in Business Information Processing (LNBIP) 96, Springer, 2012, pp. 98-116

[8] H. Dudycz., The Topic Map as a Visual Representation of Economic Knowledge (in Polish), Wrocław University of Economics, Wrocław, 2013

[9] T. R. Gruber, Toward Principles for the Design of Ontologies Used for Knowledge Sharing, Technical Report KSL, Knowledge Systems Laboratory, Stanford University, 1993, http://tomgruber.org/writing/onto-design.pdf 
[10] M. Aruldoss, D. Maladhy and V. Prasanna Venkatesan, A framework for business intelligence application using ontological classification, International Journal of Engineering Science and Technology, 2011, vol. 3 , no. 2 , pp. 1213-1221

[11] A. Cheng, Y.-C. Lu, C. Sheu, An ontology-based business intelligence application in financial knowledge management system, Expert Systems with Applications, 2009, vol. 36, issue 2, part 2, pp. 36143622

[12] B. Neumayr, M. Schrefl, K. Linner, Semantic cockpit: an ontologydriven, interactive Business Intelligence tool for comparative data analysis, in: Advances in Conceptual Modeling. Recent Developments and New Directions, Lecture Notes in Computer Science (LNCS) 6999, Springer-Verlag Berlin Heidelberg 2011, pp. 55-64

[13] F. Pinto, M. F. Santos and A. Marques, Ontology based data mining A contribution to business intelligence, 10th WSEAS International Conference on Mathematics and Computers in Business and Economics (MCBE '09), Czech Republic, 2009, March 23-25, pp. 210-216.

[14] H. Saggion, A. Funk, D. Maynard and K. Bontcheva, Ontology-based information extraction for business intelligence, in: Proceedings of the 6th International Semantic Web Conference and 2nd Asian Semantic Web Conference, Busan, Springer, Berlin/Heidelberg, 2007, pp. 843856.

[15] D. Sell, D. C. da Silva, F. D. Beppler, M. Napoli, F. B. Ghisi, R. Pacheco and J. L. Todesco, SBI: a semantic framework to support business Intelligence, in Proceeding of the first international workshop on Ontology-supported business intelligence, Article no. 11, ACM New York, 2008.

[16] J. Korczak, H. Dudycz and M. Dyczkowski, "Design of financial knowledge in dashboard for SME managers", in: Proc. of the 2013 Federated Conference on Computer Science and Information Systems. Annals of Computer Science and Information Systems, vol. 1, M. Ganzha, L. Maciaszek, M. Paprzycki, Eds. Polskie Towarzystwo Informatyczne, IEEE Computer Society Press, Warsaw, Los Alamitos, CA, 2013, pp. 1111-1118

[17] M. Dyczkowski, J. Korczak and H. Dudycz, Multi-criteria evaluation of the intelligent dashboard for SME managers based on scorecard framework, in: Proc. of the 2014 Federated Conference on Computer Science and Information Systems. Annals of Computer Science and Information Systems, M. Ganzha, L. Maciaszek, M. Paprzycki, Eds., New York City, 2014, vol. 2, pp. 1147-115

[18] K. Berman, J. Knight and J. Case, Financial Intelligence, Harvard Business Review Press, Boston 2013

[19] B. Nita, Managerial Reporting (in Polish), Warszawa: PWN, 2014

[20] L. Revsine, D.W. Collins, W.B. Johnson and H.F Mittelstaedt, Financial Reporting and Analysis, McGraw Hill, New York 2012

[21] E. Schenk, C. Guittard, Towards a characterization of crowdsourcing practices, Journal of Innovation Economics \& Management, 2011, no. 7, pp. 93-107

[22] H. J. Hwang, K. Kwon and C. H. Im, Neurofeedback-based motor imagery training for brain-computer interface (BCI), Journal of Neuroscience Methods, Republic of Korea, 2009 